\title{
Dynamic Optimization of Nitrogen in Plateau Cotton Yield Functions with Nitrogen Carryover Considerations
}

\author{
Chandra Dhakal ${ }^{1}$, Kelly Lange ${ }^{2, *}$, Megha N. Parajulee ${ }^{3}$, and Eduardo Segarra ${ }^{2}$ \\ ${ }^{1}$ Department of Agricultural and Applied Economics, University of Georgia, Athens, Georgia, USA; ${ }^{2}$ Department of \\ Agricultural and Applied Economics, Texas Tech University, Lubbock, Texas, USA; and ${ }^{3}$ Department of Entomology, \\ Texas A\&M University, College Station, Texas, USA \\ ${ }^{*}$ Corresponding author. Email: kelly.lange@ttu.edu
}

\begin{abstract}
This study utilizes a dynamic programming decision model, considering an intertemporal nitrogen carryover function, combined with both linear stochastic and deterministic plateau response functions to evaluate optimal nitrogen fertilizer decision rules and net present values (NPVs) in Texas High Plains cotton production. Nitrogen recommendations and NPVs are influenced by response function choice and nitrogen-to-cotton price ratios. Results indicate the stochastic plateau function better describes the data; the optimum nitrogen recommendation is to apply approximately $40 \mathrm{lb}$. of nitrogen for each bale of cotton production when considering nitrogen carryover information.
\end{abstract}

Keywords: Carryover; cotton production; nitrogen optimization; plateau; Texas High Plains

JEL Classifications: Q10; Q24

\section{Introduction}

The Southern High Plains region of Texas (SHPT) is one of the most cotton-intensive production areas in the world. Producers in this region face challenges related to increasing input costs, volatile seed and lint prices, and limited productivity given water constraints (Parajulee and Shrestha, 2014). Irrigation water and nitrogen fertilizer are two common limiting input factors in SHPT cotton production. Declining Ogallala aquifer volume has contributed to increased proportions of dryland cotton acreage during the last 10 years (U.S. Department of Agriculture, National Agricultural Statistics Service, 2018). Additionally, cotton farmers are challenged by increasing nitrogen fertilizer prices (Bronson et al., 2006). Moreover, nitrogen is one of the most expensive inputs, accounting for $15 \%$ to $20 \%$ of cotton production costs (Smith, 2016).

Economically, optimal fertilizer rates can be obtained by maximizing expected net revenues subject to crop yield functions. The fitting of crop yield response functions to yield data has become an increasingly common method among economists to derive economic profitability models in agricultural crop production systems (Tembo et al., 2008).

Of all the functional forms developed on theoretical and empirical grounds, polynomial functions are most commonly used (Frank, Beattie, and Embleton, 1990; Harper et al., 2012; Heady and Dillon, 1961; Hurley, Oishi, and Malzer, 2005; Roberts, English, and Larson, 2006; Xu et al., 2009). This functional form is assumed to be linear in parameters with no plateau growth and often overestimates maximum yield and optimal fertilizer recommendation (Ackello-Ogutu, Paris, and Williams, 1985; Lanzer and Paris, 1981). The linear response plateau (LRP) model, proposed by Cate and Nelson (1971), has become popular in recent years. This functional form 
is based on the agronomic principle of "law of minimum" formulated by Von Liebig (1855), per which crop growth is governed by the most limiting ("minimum") factor until another factor becomes limiting. The constant yield with an additional input represents the yield potential of the crop, also referred to as the plateau yield. The point where the plateau begins corresponds to the optimal input. Contrary to polynomial response forms, the LRP model does not allow for nutrient substitution and implies a sharp transition to a plateau maximum.

Past studies have argued that LRP models explained crop response to fertilizers at least as well as polynomial forms, if not better (Ackello-Ogutu, Paris, and Williams, 1985; Anderson and Nelson, 1975; Babcock and Blackmer, 1994; Grimm, Paris, and Williams, 1987; Lanzer and Paris, 1981; Paris, 1992; Perrin, 1976; Waugh, Cate, and Nelson, 1973). However, plateau response functions have often assumed that inputs are perfectly controllable, and plateau is deterministic (Cox, 1996; Llewelyn and Featherstone, 1997; Paris and Knapp, 1989). In reality, agricultural inputs are not fully controlled and are often hard to quantify (Sher and Amir, 1994), and crop response to inputs can vary with years and field locations (Cerrato and Blackmer, 1990). Further, the nonrandom plateau function does not consider potential interaction between the primary input (nitrogen) and environmental factors when modeling crop yield response (Boyer et al., 2015). With the increasing criticism of the deterministic plateau, focus shifted to stochastic plateau functional forms. Makowski and Wallach (2002) considered the stochastic plateau, and Berck and Helfand (1990) examined randomness in plateau. Raun et al. (2002) considered randomness of inputs, plateau, and intercept but did not consider random effects. Paris (1992) found a switching regression model supported the Von Liebig hypothesis.

Recently, Tembo et al. (2008) modified the LRP by including uncorrelated random effects that shifted both the intercept and plateau, which allowed them to be stochastic, and developed the linear response stochastic plateau (LRSP) functional form. The LRSP functional form includes two independent random effects: year random effects and plateau year random effects. The year random effect acts as an intercept, and the plateau year random effect allows year-to-year variation of expected yield potential. The study also developed a direct formula to estimate optimal fertilizer rates that maximize expected returns. The LRSP function has been used extensively to model crop yields to fertilizers in cotton, wheat, forage, corn, potatoes, and sorghum (Asci, Borisova, and VanSickle, 2015; Biermacher et al., 2009; Boyer et al., 2013, 2015; Brorsen and Richter, 2012; Harmon et al., 2016; Kaitibie et al., 2003, 2007; Tumusiime et al., 2011; Zhou et al., 2015).

Although both deterministic- and stochastic-plateau-type models have been popularly utilized with large degrees of predictability in many production situations, these models could have an additional random effect on the response portion and might result in suboptimal fertilizer decision rules for the single-year planning model because of the dynamic nature of fertilizer in soil. Crops acquire nitrogen from two sources: applied nitrogen in the current crop production year and carryover nitrogen from previous years (Lemon et al., 2009). Further, carryover nitrogen at a given time depends on previous nitrogen application and prior levels of residual nitrogen. Without accounting for carryover information in a dynamic model, these plateau-type models may not optimize production efficiency and environmental sustainability in the long run. Consideration of carryover nitrogen prior to nitrogen application changes the producer's decision framework from maximizing expected profit in a given year to maximizing the net present value (NPV) of net returns over a planning horizon. This is because application levels in a given year are based on their application rates from the previous year. Given this, many Texas High Plains cotton producers use soil test data to adjust year-to-year nitrogen application regimes.

Studies have shown that accumulation of carryover fertilizers significantly affects crop yield and net revenue in succeeding years (Harmon et al., 2016; Harper et al., 2012; Jomini et al., 1991; Raun et al., 1998; Segarra et al., 1989). However, the degree of nitrogen accumulation varies with the soil environment (e.g., rainfall) and soil health (e.g., available soil microbes, cation exchange, and organic matter). It may be noted that geographic variation influences nitrogen carryover effects. In arid regions with dry soil, nitrogen uptake is often less than that seen in higher 
rainfall areas. This increases the likelihood that residual nitrogen will be left in the soil (Huang, Lu, and Uri, 2001). Thus, it can be speculated that the degree of nitrogen carryover is likely greater in a low-rainfall area such as the Texas High Plains. Soil nitrogen testing provides carryover information to assist producers in improving the application of nitrogen fertilizer, including determination of whether nitrogen fertilizer is needed, and avoidance of excess nitrogen fertilizer use, which reduces fertilizer costs.

Fertilizer carryover effects were discussed previously by Heady and Dillon (1961), Fuller (1965), Anderson (1967), Kennedy et al. (1973), Godden and Helyar (1980), and Kennedy (1981). These studies resulted in the derivation of the optimality condition for fertilizer application with carryover effects using a dynamic optimization approach. However, most classical dynamic programming models have assumed either polynomial or deterministic plateau yield response functional forms (Harper et al., 2012).

Economic literature on simultaneous use of plateau yield function and dynamic optimization of fertilizers using carryover information is limited. Recent work by Harmon et al. $(2016,2017)$ determined the value of soil test information for potassium in upland cotton production utilizing plateau functions; however, studies using the stochastic plateau model, while considering carryover effects, in nitrogen management decisions are scarce. Thus, this article utilizes stochastic and plateau functions to consider changes in nitrogen fertilizer recommendation levels, when considering carryover, with respect to nitrogen-to-cotton price ratios. Using a stochastic plateau crop yield function in a dynamic programming approach could improve nitrogen fertilizer recommendation levels and offer more efficient cotton production.

In this study, we combine stochastic and nonstochastic plateau functions in a deterministic dynamic optimization model, which considers an intertemporal nitrate nitrogen residual function. We examine optimal nitrogen rates, which maximize expected yield, expected profits, and NPV of returns using stochastic and deterministic plateau functions considering carryover nitrogen. This allows us to examine the value of using a stochastic plateau function over its deterministic counterpart, while incorporating nitrogen carryover information under different input-output price scenarios. Specifically, this research uses Tembo et al.'s (2008) stochastic plateau yield function with Kennedy's $(1986,1988)$ dynamic programming model to make methodological contributions in the estimation of optimal input decision rules in production economics.

\section{Experimental design and data}

A long-term field experiment was conducted on a 5-acre, subsurface drip-irrigated field at the Texas A\&M AgriLife Research farm near Plainview, Texas (34.147 N, -101.947 W). Five nitrogen application rates $(0,50,100,150$, and $200 \mathrm{lb}$./acre) were applied to the same experimental units consistently for 14 consecutive years from 2002 to 2015. The experiment consisted of a randomized block design with five treatments and five replications. Residual soil nitrogen was monitored annually before applying nitrogen treatment, by taking two 24 -inch core samples from each plot. Samples were sent to Ward Laboratories in Kearney, Nebraska, for analysis. Regionally well-adapted commercial cotton cultivars were used over the duration of this study, including PM2379RR (2002, 2003, 2004, and 2005), FM960B2R (2006, 2007, 2008, 2009, and 2010), DP104B2RF (2011), FM9063B2RF (2012, 2013, and 2014), and FM9180B2F (2015). Change in cultivars over the study duration was necessitated because of new cultivar development and discontinuation of older cultivars. Average lint yield from each plot was calculated in pounds per acre for each year.

Analysis of variance (ANOVA) for yield and net returns by applied nitrogen with pairwise comparison based on the least significant difference is shown in Table 1. These results indicate that zero-applied nitrogen (i.e., plots that received no nitrogen augmentation) produced the lowest yield, and yield increased linearly with nitrogen augmentation until the highest yield occurred 
Table 1. Least square means of cotton lint yield and net return above nitrogen cost, 2002-2015

\begin{tabular}{|c|c|c|c|c|}
\hline $\begin{array}{l}\text { Applied Nitrogen } \\
\text { (lb./acre) }\end{array}$ & $\begin{array}{c}\text { Carryover Nitrogen } \\
\text { (lb./acre) }\end{array}$ & $\begin{array}{c}\text { Yield } \\
\text { (lb./acre) }\end{array}$ & $\begin{array}{c}\text { Gross Revenue }{ }^{a, b} \\
\text { (\$/acre) }\end{array}$ & $\begin{array}{l}\text { Net Returns }{ }^{a, c} \\
(\$ / a c r e)\end{array}$ \\
\hline 0 & $\begin{array}{c}23.28 \\
(17.94)\end{array}$ & $\begin{array}{l}908.64^{c} \\
(308.47)\end{array}$ & $\begin{array}{l}590.61^{C} \\
(200.50)\end{array}$ & $\begin{array}{c}590.61 \\
(200.50)\end{array}$ \\
\hline 50 & $\begin{array}{c}28 \\
(20.49)\end{array}$ & $\begin{array}{c}1,112.73^{\text {B }} \\
(373.91)\end{array}$ & $\begin{array}{l}723.27^{\text {B }} \\
(243.04)\end{array}$ & $\begin{array}{c}698.27 \\
(243.04)\end{array}$ \\
\hline 100 & $\begin{array}{c}45.92 \\
(58.35)\end{array}$ & $\begin{array}{c}1,208.644^{A B} \\
(414.77)\end{array}$ & $\begin{array}{l}785.62 \mathrm{AB} \\
(269.60)\end{array}$ & $\begin{array}{c}735.62 \\
(269.60)\end{array}$ \\
\hline 150 & $\begin{array}{c}40.32 \\
(26.46)\end{array}$ & $\begin{array}{c}1,270.43^{A} \\
(488.91)\end{array}$ & $\begin{array}{l}825.78^{A} \\
(317.79)\end{array}$ & $\begin{array}{c}750.78 \\
(317.79)\end{array}$ \\
\hline 200 & $\begin{array}{c}66.07 \\
(61.56)\end{array}$ & $\begin{array}{c}1,270.25^{A} \\
(481.32)\end{array}$ & $\begin{array}{l}825.67^{A} \\
(312.86)\end{array}$ & $\begin{array}{c}725.67 \\
(312.86)\end{array}$ \\
\hline
\end{tabular}

aThe selected prices are $\$ 0.50 / \mathrm{lb}$. and $\$ 0.65 / \mathrm{lb}$. for nitrogen and cotton, respectively.

${ }^{\mathrm{b}}$ Gross Revenue $=$ Yield $\times \$ 0.65 / \mathrm{lb}$.

${ }^{c}$ Net Returns $=$ Gross Revenue - (Applied Nitrogen $\times \$ 0.50 / \mathrm{lb}$.).

Note: Values in the same column and with the same uppercase letters are not significantly different, and figures in parentheses indicate standard deviation.

with $150 \mathrm{lb}$./acre of applied nitrogen. The yield achieved with a nitrogen application rate of $150 \mathrm{lb}$./acre was significantly higher than that with zero and $50 \mathrm{lb}$./acre of applied nitrogen but was not significantly different from 100 and $200 \mathrm{lb}$./acre of applied nitrogen. The results imply that optimum applied nitrogen lies somewhere between 50 and $150 \mathrm{lb}$./acre of applied nitrogen. The weakness of ANOVA is that only discrete choices are considered, so the single optimum point within the given ranges cannot be identified.

Prices of nitrogen and lint cotton (in dollars per pound) used in this study were acquired from Texas A\&M AgriLife Extension Service budgets prepared for the South Plains District of Texas (Smith, 2016). Five sets of lint and nitrogen prices were used to estimate the different levels of return streams via NPV analysis. Ten-year average prices were taken as a reference, $\$ 0.65 / \mathrm{lb}$. and $\$ 0.50 / \mathrm{lb}$. for lint and nitrogen, respectively, and four additional price sets corresponding to $20 \%$ and $40 \%$ below and above the average prices. Thus, the five price scenarios for lint and nitrogen prices per pound, respectively, were $\$ 0.39$ and $\$ 0.30, \$ 0.52$ and $\$ 0.40, \$ 0.65$ and $\$ 0.50, \$ 0.78$ and $\$ 0.60$ and $\$ 0.91$ and $\$ 0.70$. A 10 -year planning horizon and a 35-lb./acre initial condition of residual nitrate nitrogen were also considered. Further, a 5\% discount rate was applied to represent the opportunity cost of land in cotton production, as per previous studies (Harper et al., 2012).

Normal data are an underlying assumption for maximum likelihood estimation, so assessment for normality of residuals is a prerequisite. Tests for normality of residuals were applied using both graphic and numeric methods. Results showed that both the Kolmogorov-Smirnov test and the Cramer-von Mises test were not significant $(P=0.18, P=0.16)$; thus, there is evidence that the residuals follow the normal distribution. A simple linear model was run over the study period and showed a yield trend slope of -7.24 with a standard error of 6.06. That is, the Student $t$-test results did not show a significant time trend, so time trend was not considered when modeling cotton yield response. Other studies have found considerable genetic improvement in cotton using GMO (genetically modified organism) varieties (Ouedraogo, Brorsen, and Arnall, 2016); however, we find no similar trend over time, likely because of the use of non-GMO varieties in this study.

\section{Conceptual and empirical models}

In the present study, nitrogen is considered a limiting factor so that augmentation of nitrogen leads to a linear increment in cotton yield. Under the concept of zero elasticity of substitution for all levels of nitrogen, the Von Liebig hypothesis of "law of minimum" infers the notion of 
plateau (Anderson and Nelson, 1975; Lanzer and Paris, 1981; Paris, 1992; Perrin, 1976). The notion of plateau implies that a cotton crop responds to a supply of nitrogen at a constant slope until maximum potential yield (plateau) is reached. Once the plateau is reached, nitrogen will no longer be a limiting factor, and an additional unit of nitrogen suggests wastage of the input and economic burden to producers. The relationship between nitrogen application and the attainment of plateau is illustrated in Tembo et al. (2008).

\subsection{Linear response plateau function}

Using LRP functional form, the lint yield response to nitrogen can be expressed as follows:

$$
y_{i t}=\min \left(\beta_{0}+\beta_{1} N T_{i t}, \mu\right)+\tau_{t}+\epsilon_{i t},
$$

where $y_{i t}$ is lint yield (pounds per acre) from plot $i$ in period $t, \beta_{0}$ is response at the origin, $\beta_{1}$ is the linear slope parameter for nitrogen, $N T_{i t}$ is total nitrogen from plot $i$ in period $t, \mu$ is the plateau, $\tau_{t} \sim N\left(0, \sigma_{\tau}^{2}\right)$ is an intercept year random effect, and $\epsilon_{i t} \sim N\left(0, \sigma_{\epsilon}^{2}\right)$ is a random disturbance term. Both error terms are assumed to be i.i.d. (independent and identically distributed), and total variance $\left(\sigma_{T}^{2}\right)=\sigma_{\epsilon}^{2}+\sigma_{\tau}^{2}$.

The function is continuous, but derivatives do not exist with respect to $N T$ at the knot point where the linear response and plateau are joined (Park et al., 2007). The optimal level of nitrogen $\left(N T_{i t}^{*}\right)$ can be determined based on equation (1). A nonstochastic LRP function will show constant positive marginal value product (MVP) when $\beta_{0}+\beta_{1} N T_{i t}<\mu$, and nitrogen should be applied until MVP $\left(P_{t} \beta_{1}\right.$, where $P_{t}$ is the price of lint [dollars per pound] in year $\left.t\right)$ equals marginal fixed cost minus the value of fertilizer savings in the current year, because of carryover effects of the previous year's fertilizer application $(k)$. Thus, the optimal nitrogen level for LRP would be either zero or the nitrogen level to reach the plateau (Boyer et al., 2013; Park et al., 2007; Tembo et al., 2008):

$$
\begin{gathered}
N=\left\{\begin{array}{l}
N T * \text { if } p_{t} \beta_{1}>k \\
0 \text { otherwise }
\end{array},\right. \\
N T *=\frac{\mu-\beta_{0}}{\beta_{1}} .
\end{gathered}
$$

\subsection{Linear response stochastic plateau function}

Following Tembo et al. (2008), the LRSP to model lint yield response to nitrogen is

$$
y_{i t}=\min \left(\beta_{0}+\beta_{1} N T_{i t}, \mu+u_{t}\right)+\tau_{t}+\epsilon_{i t},
$$

where $u_{t} \sim N\left(0, \sigma_{u}^{2}\right)$ is a plateau year random effect that enters nonlinearly, and other terms are as defined previously. Total nitrogen $\left(N T_{i t}\right)$ is used to model the yield function based on model selection criteria such as Akaike information criterion, Bayesian information criterion, and likelihood ratio test, rather than including both applied nitrogen $\left(N A_{i t}\right)$ and carryover nitrogen $\left(N R_{i t}\right)$. Three residual terms are assumed to be i.i.d., and total variance $\left(\sigma_{T}^{2}\right)=\sigma_{u}^{2}+\sigma_{\tau}^{2}+\sigma_{e}^{2}$.

Based on the censored normal distribution theorem developed for Tobit models and applying chain rules, one can derive the optimal total nitrogen level as developed by Tembo et al. (2008, p. 427):

$$
N T_{i t}^{*}=\frac{1}{\beta_{1}}\left(\phi^{-1} \sigma_{u}^{2}-\beta_{0}+\mu\right),
$$

where $\Phi^{-1}=\Phi^{-1}\left(1-\frac{k}{p_{t} \beta_{1}}\right)$ is the inverse of the standard normal cumulative distribution function assuming $\left(\beta_{1} \geq \frac{k}{p_{t}}\right)$; otherwise zero nitrogen would be optimal. Alternatively, it can be expressed as follows: 


$$
N T_{i t}^{*}=\frac{1}{\beta_{1}}\left(\mu+Z_{\alpha} \sigma_{u}-\beta_{0}\right),
$$

where $Z_{\alpha}=\left[\frac{\beta_{0}+\beta_{1}\left(N T_{i t}\right)-\mu}{\sigma_{u}}\right]$ is the standard normal variate with $\alpha=1-\emptyset=\frac{k}{p_{t} \beta_{1}}$, and the expected profit-maximizing yield is calculated by Tembo et al. (2008) as

$$
E\left(y_{i t}\right)=(1-\Phi) a+\Phi\left(\mu-\frac{\sigma_{u} \phi}{\Phi}\right)
$$

where $a=\beta_{0}+\beta_{1} N T_{i t}, \Phi=\Phi\left[\frac{a-\mu}{\sigma_{u}}\right]=\operatorname{prob}(\mu \leq a)$ is the cumulative normal distribution function and $\phi=\phi\left[\frac{a-\mu}{\sigma_{u}}\right]$ is the standard normal density function. Maximum likelihood parameter estimates for equations (1) and (3) were obtained using the NLMIXED procedure in SAS 9.4 (Brorsen and Ouedraogo, 2015; SAS Institute Inc., 2016).

In the case of symmetric distribution, which occurs when $k /\left(p \beta_{1}\right)$ equals 0.5 , the optimum level of nitrogen for the nonstochastic plateau model would be equal to that for the stochastic plateau model (Tembo et al., 2008). When the distribution is symmetric and $k /\left(p \beta_{1}\right)<0.5$, the optimal level of nitrogen under the stochastic plateau model is higher than with a nonstochastic model if all other parameters are the same.

\subsection{Carryover function}

The linear carryover function is a commonly used functional form (Harper et al., 2012; Park et al., 2007), where carryover nitrogen in the next production year is linearly proportional to the total available nitrogen in the soil in the current year. The nitrogen carryover function used here is a linear function of total available nitrogen adapted from Kennedy (1986) and used by Segarra et al. (1989) for nitrogen in cotton production. Further, we assume that applied and residual nitrogen levels have different effects on the amount of nitrogen being carried over to the next period because of soil nitrate-nitrogen dynamics. The linear carryover function is given by

$$
N R_{i t+1}=\alpha_{o}+\alpha_{1} N A_{i t}+\alpha_{2} N R_{i t}+\tau_{t}+\varepsilon_{i t+1},
$$

where $\alpha_{1}$ and $\alpha_{2}$ are parameters; $N A_{i t}$ and $N R_{i t}$ are the amounts of applied and carryover nitrogen from plot $i$ in period $t$, respectively; $\tau_{t} \sim N\left(0, \sigma_{t}^{2}\right)$ is an intercept year random effect that captures the year-to-year variation of residual nitrogen in soil; and $\epsilon_{t+1} \sim N\left(0, \sigma_{\epsilon}^{2}\right)$ is a random disturbance term. Both error terms are assumed to be i.i.d.

\subsection{Dynamic programming approach}

A risk neutral, profit-maximizing cotton producer can choose an amount of nitrogen fertilizer $\left(N A_{t}\right)$ to be applied for each production year $(t),(t+1 \ldots T)$ with carryover nitrate nitrogen $\left(N R_{t}\right)$, which maximizes the NPV of a stream of returns over a planning horizon (Kennedy, 1986; Kennedy et al., 1973). The optimality condition of this scenario can be expressed as follows:

$$
\begin{gathered}
{ }_{N A_{t}}^{M A X} N P V=\sum_{t=1}^{T} \delta^{t}\left[P_{t} \times Y_{i t}\left(N T_{i t}\right)-C_{t} \times N A_{i t}\right] \\
\text { subject to } N T_{i t}=N A_{i t}+N R_{i t}, \\
N R_{i t+1}=\alpha N T_{i t}, \\
N A_{i t}, N R_{i t}, N T_{i t} \geq 0
\end{gathered}
$$

with $N R_{1}$ is given:

$$
N R_{i T+1}=0,
$$




$$
N R_{0}=N R(0),
$$

where NPV is the per acre present value of returns (in dollars); $T$ is the length of the decisionmaker's planning horizon in years; $N T_{i t}, P_{t}$, and $C_{t}$ are defined previously; $Y_{i t}\left(N T_{i t}\right)$ is the cotton yield function (pounds per acre) in year $t ; \delta=(1+r)^{-1}$ is the discount factor, where $r$ is the discount rate reflecting the producer's opportunity cost of time; and $\alpha$ is the carryover coefficient $(0 \leq \alpha \leq 1)$, which is a proportion of available nitrogen fertilizer in period $t+1$ that is carried over from nitrogen application in period $t$. The decision variable is $N A_{i t}$, the amount of nitrogen to be applied in each crop season. The static variable is residual $N R_{i t}$ remaining in the soil before planting next year's cotton. Fixed costs were ignored because they do not affect the determination of the optimal amount of nitrogen to apply. Equation (8) was estimated using the general algebraic modeling system (Segarra et al., 1989).

The optimal amount of nitrogen $\left(\mathrm{NA}^{*}\right)$ to apply each year can be solved using a recursive functional equation (Bellman, 1957), which is given by

$$
F_{t}\left\{N R_{i t}\right\}=\max _{i t}^{\max }\left\{\delta P_{t} Y_{i t}\left(N A_{i t}^{*}+N R_{i t}\right)-C_{t} \times N A_{i t}^{*}+\delta F_{t+1}\left[\alpha\left(N A_{i t}^{*}+N R_{i t}\right)\right]\right\},
$$

with $F_{T+1}\left\{N T_{i T+1}\right\}=0$, as a terminal condition, where $F_{t}\left\{N R_{i t}\right\}$ is the present value of net returns (dollars per pound) from optimal nitrogen application $\left(N A_{i t}^{*}\right)$ in each year of the period $t$ considering nitrogen carryover $N R_{i t}, N A_{i t}$ is the amount of nitrogen applied from plot $i$ in year $t, \delta=$ $(1+r)^{-1}$ is the discount factor, $P_{t}$ is the price of lint (dollars per pound) in year $t, C_{t}$ is the cost of nitrogen (dollars per pound) in year $t, Y_{i t}$ represents cotton yield (pounds per acre) from plot $i$ in year $t, \alpha$ is a carryover parameter $(0 \leq \alpha \leq 1)$, and the proportion of fertilizer available in period $t\left(N R_{i t}+N A_{i t}\right)$ carried over to period $t+1$.

The envelope theorem (Leonard and van Long, 1992) is applied to estimate the value of carryover fertilizers to subsequent years. Differentiating equation (14) with respect to $N A_{i t}$ gives the first-order necessary condition for an interior maximum, which is as follows:

$$
\frac{\partial F_{t}}{\partial N A_{i t}}=\delta P_{t} \frac{\partial Y_{i t}}{\partial N A_{i t}}-C_{t}+\delta \alpha \frac{\partial F_{t+1}}{\partial N R_{i t+1}}=0 .
$$

Again, differentiating equation (14) with respect to $N R_{t}$, the first-order condition for net return maximization (Harper et al., 2012) is as follows:

$$
\frac{\partial F_{t}}{\partial N R_{i t}}=\delta_{t} P_{t} \frac{\partial Y_{i t}}{\partial N A_{i t}}+\delta \alpha \frac{\partial F_{t+1}}{\partial N R_{i t+1}}=0 .
$$

Because this is a linear term, the marginal responses to total, applied, and carryover nitrogen are identical (Kennedy, 1986), and we see that

$$
\begin{gathered}
\frac{\partial N T_{i t}}{\partial N A_{i t}}=\frac{\partial N T_{i t}}{\partial N R_{i t}}=1, \text { and } \\
\frac{\partial Y_{i t}}{\partial N T_{i t}}=\frac{\partial Y_{i t}}{\partial N A_{i t}}=\frac{\partial Y_{i t}}{\partial N R_{i t}} ;\left(\text { by chain rule), we get, } \frac{\partial N R_{i t+1}}{\partial N A_{i t}}=\alpha .\right.
\end{gathered}
$$

From equations (15), (16), and (17), this can be written as

$$
\frac{\partial F_{t}}{\partial N R_{i t}}=C_{t}
$$

which implies that the value of an additional unit of nitrogen fertilizer being carried over from the previous year to the current year should be equal to the per unit cost of nitrogen in the current year, irrespective of the amount being carried over. 
Updating $\frac{\partial F_{t}}{\partial N R_{i t}}$ for a single period $t+1$ and from equations (16) and (18), we get

$$
\delta P_{t} \frac{\partial Y_{t}}{\partial N T_{i t}}=C_{t}-\delta \alpha C_{t+1}=k .
$$

For the sake of convenience, we assume $C_{t}-\delta_{t} \alpha C_{t+1}$ to be $k$, which states that the present MVP of fertilizer should be equal to the opportunity cost of the marginal unit of nitrogen fertilizer to achieve the optimality condition. If a cotton farmer does not consider nitrogen carryover, then $N R_{t}=0$ and the optimal condition for a single-period nitrogen application becomes

$$
\delta P_{t} \frac{\partial Y_{t}}{\partial N T_{t}}=C_{t}
$$

This suggests that the single-year planning model yields suboptimal or inefficient levels of nitrogen application, and the discounted nitrogen fertilizer savings remain in the soil until the period is no longer considered. Further, Tembo et al. (2008, p. 426) showed

$$
\frac{\partial Y_{t}}{\partial N T_{t}}=\beta_{1}(1-\Phi)
$$

where $\Phi=\Phi\left[\frac{\beta_{0}+\beta_{1} N T_{t}-\mu}{\sigma_{u}}\right]$ is a standard normal cumulative distribution function and $0 \leq \phi \leq 1$.

Substituting equation (21) into equation (20) produces the optimality condition as

$$
\delta_{t} P_{t} \beta_{1}(1-\Phi)=k \text {. }
$$

These savings $\left(\delta \alpha C_{t+1}\right)$, which are the discounted savings from nitrogen fertilizer carried over to the next year, were subtracted from the price because fertilizer carryover reduces the amount of applied fertilizers needed in the following years. Equation (23) states that for the optimality condition $\left(N A_{t}=N A_{t}^{*}\right)$, the profit-maximizing condition occurs when the present value of the current crop and input savings from future fertilizer equal the expected fertilizer cost in subsequent years. The general rule of dynamic optimization is that fertilizer be applied up to the level where the expected present value of returns from the current year crop and future fertilizer application savings obtained from the marginal unit of fertilizer equal the current fertilizer cost (Kennedy, 1986).

\subsection{Yield response function estimation}

The models were constructed using the PROC NLMIXED procedure in SAS using maximum likelihood estimation methods. The NLMIXED procedure maximizes the marginal log-likelihood functions, directly using the theory of nonlinear mixed effects models (Wolfinger, 1999).

The random disturbance term and intercept year random effect enter the functions linearly, whereas the plateau year random effect enters nonlinearly, which does not have a closed form solution and can only be approximated numerically. The most common problem associated with nonlinear optimization is obtaining convergence, and the optimization algorithm may converge to a local instead of a global optimum (SAS Institute Inc., 2013). To address this, first-order approximation was used to obtain starting values, and various combinations of starting values were then used as the starting points in nonadaptive, 31-point Gaussian quadrature, which is much less likely to fail to converge or converge to a local optimum (Brorsen and Richter, 2012). The Newton-Raphson optimization algorithm was used to carry out the maximization.

\section{Results}

\subsection{Parameter estimates}

Parameter estimates for cotton lint yield response to total nitrogen, using both functional forms, are reported in Table 2. All parameters and variance components were significantly different from 
Table 2. Cotton yield response to nitrogen with stochastic and deterministic plateau functions

\begin{tabular}{|c|c|c|c|c|}
\hline \multirow[b]{2}{*}{ Parameter } & \multicolumn{2}{|c|}{ Stochastic Plateau } & \multicolumn{2}{|c|}{ Deterministic Plateau } \\
\hline & Estimate & Standard Error & Estimate & Standard Error \\
\hline Intercept $\left(\beta_{0}\right)$ & $817.12^{\star \star \star}$ & 72.88 & $819.74^{\star \star \star}$ & 84.75 \\
\hline Slope of nitrogen $\left(\beta_{0}\right)^{\mathrm{a}}$ & $3.94^{\star \star \star}$ & 0.68 & $3.90^{\star \star *}$ & 0.68 \\
\hline Plateau yield ( $\mu$ ) (lb./acre) & $1,225^{\star \star \star}$ & 80.17 & $1,226^{\star \star \star}$ & 77.37 \\
\hline Plateau random effect $\left(\sigma_{u}^{2}\right)^{\mathrm{b}}$ & $31,711^{\star \star \star}$ & 16.36 & - & - \\
\hline Intercept random effect $\left(\sigma_{v}^{2}\right)^{b}$ & $55,247^{\star \star \star}$ & 4.59 & $80,235^{\star \star \star}$ & 6.44 \\
\hline Random disturbance $\left(\sigma_{e}^{2}\right)$ & $43,123^{\star \star \star}$ & $3,512.71$ & $50,358^{\star \star \star}$ & $4,027.19$ \\
\hline Plateau nitrogen (lb./acre) & $104^{\star \star \star}$ & 16.85 & $105^{\star \star \star}$ & 11.78 \\
\hline Covariance $\left(\sigma_{u}^{2}, \sigma_{v}^{2}\right)$ & 75.12 & & - & \\
\hline Akaike information criterion & $4,507.60$ & & $4,536.40$ & \\
\hline Bayesian information criterion & $4,511.40$ & & $4,539.60$ & \\
\hline-2 Log likelihood & $4,495.60$ & & $4,526.40$ & \\
\hline Observations & 377 & & & \\
\hline
\end{tabular}

aslope of nitrogen is for total nitrogen.

${ }^{b}$ Random effects are for year.

Note: Asterisks $\left({ }^{*},{ }^{\star \star}\right.$, and $\left.{ }^{\star \star \star}\right)$ indicate $P<0.10, P<0.05$, and $P<0.01$, respectively (two-tailed test).

Source: Data from Texas A\&M AgriLife Research farm near Plainview, Texas, 2002-2015.

zero at the $1 \%$ level, based on Wald $t$-tests. The plateau random effect was significant with the LRSP model, indicating that the plateau is stochastic.

Goodness of fit for both stochastic and deterministic plateau functions was evaluated using the likelihood ratio test with 1 degree of freedom. The calculated likelihood ratio test statistic was 30.8 with a critical chi-square value of 6.63 , providing evidence that the stochastic plateau model fit the cotton yield data relatively better than its deterministic counterpart. These results agreed with previous studies (Boyer et al. 2012, 2013; Harmon et al. 2016; Kaitibie et al., 2007).

The expected plateaus of cotton lint yield were 1,226 lb./acre and 1,225 lb./acre for LRP and LRSP functions, respectively. The estimated marginal productivity of total nitrogen was slightly higher with the LRSP model (3.94) than with LRP (3.90), so less nitrogen was needed to reach the plateau. Tembo et al. (2008) and Tumusiime et al. (2011) emphasized attenuation bias to explain the lower estimates of nitrogen productivity with the deterministic plateau model. The MVP of nitrogen with the LRSP model, when the price of cotton was $\$ 0.65$, was $\$ 2.56 / 1 \mathrm{~b}$. Further, the threshold level of total nitrogen required to achieve a plateau knot was slightly higher for LRP (105 lb./acre) than that for LRSP (104 lb./acre).

\subsection{Nitrate nitrogen carryover function}

The nitrate nitrogen carryover function describes the rates at which both applied nitrogen and nitrate nitrogen, residual available in the soil from previous years, become available to the current year's crop. The nitrogen carryover function is estimated via the linear mixed effects model using maximum likelihood estimation as shown in Table 3.

Positive signs for an intercept and lag of applied and residual nitrogen were expected in the nitrogen carryover function. Both applied and residual nitrogen variables were used in carryover 
Table 3. Soil nitrogen carryover function parameter estimates

\begin{tabular}{lcc}
\hline Parameter & Estimate & Standard Error \\
\hline Intercept $\left(\alpha_{0}\right)$ (lb./acre) & $15.95^{\star \star \star}$ & 4.99 \\
\hline Slope of lag applied nitrogen $\left(\alpha_{1}\right)$ (lb./acre) & $0.06^{\star \star}$ & 0.03 \\
\hline Slope of lag residual nitrogen $\left(\alpha_{2}\right)$ (lb./acre) & $0.47^{\star \star \star}$ & 0.05 \\
\hline Intercept random effect $\left(\sigma_{v-1}^{2}\right)^{\mathrm{a}}$ & $219.20^{\star \star}$ & 112.90 \\
\hline Random disturbance $\left(\sigma_{e}^{2}\right)$ & $908.06^{\star \star \star}$ & 73.27 \\
\hline -2 Log likelihood & $3,174.10$ & \\
\hline Likelihood ratio test & $19.97^{\star \star \star}$ & \\
\hline Observations & 377 & \\
\hline
\end{tabular}

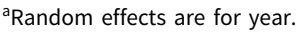

Note: Asterisks $\left({ }^{\star},{ }^{\star \star}\right.$, and $\left.{ }^{\star \star \star}\right)$ indicate $P<0.10, P<0.05$, and $P<0.01$, respectively (two-tailed test). Source: Data from Texas A\&M AgriLife Research farm near Plainview, Texas, 2002-2015.

functions (variance inflation factor was 1.12, indicating no evidence of multicollinearity). ${ }^{1}$ All parameters were significantly different from zero at any conventional confidence level, except for applied nitrogen, which was significant at the 5\% significance level. The estimated intercept implies that nearly $16 \mathrm{lb}$./acre of nitrogen was added each year in soil, as plant-available nitrogen may become accessible through natural phenomena such as the decay and breakdown of organic matter, weathering of soil particles, nitrogen fixation by leguminous weedy plants between two cropping seasons, and so forth. Different carryover coefficients for applied and residual nitrogen were observed. The estimated carryover coefficient for applied nitrogen was 0.06 , which indicated that for each $100 \mathrm{lb}$./acre of applied nitrogen, soil nitrogen (in the form of nitrate nitrogen) increased by $6 \mathrm{lb}$./acre the following year. Thus, $6 \%$ of the previous year's total applied nitrogen carried over to the current year as residual nitrate nitrogen. Interestingly, the carryover coefficient for residual nitrogen indicated that nearly $47 \%$ of residual nitrogen was not used by the plant and carried over to the following period. This result indicates that nitrogen form, applied versus residual, affects carryover amounts differently. This finding is in line with Stoecker and Onken (1989), who showed that the effect of residual soil nitrogen on cotton yield was significantly different from that of applied nitrogen. We speculate that residual nitrate nitrogen is more stable in the soil profile, and less vulnerable to nitrogen losses, than nitrogen augmented in the soil in the current year. Because amounts of nitrate nitrogen in soil are affected by nitrogen application timing, form of nitrogen applied, rate of application, and amount of irrigation and rainfall, it is not surprising that the carryover coefficient of a more stable residual nitrogen is greater than the edaphically vulnerable applied nitrogen in our study. Using the likelihood ratio test, the null hypothesis of lack of random effects was rejected (likelihood statistics: 19.97 and $\chi_{1,0.05}^{2}=3.84$ ).

\subsection{Optimal nitrogen application rules}

The optimal nitrogen level for deterministic plateau was either $104 \mathrm{lb}$./acre when the price of nitrogen was less than the sum of MVP ( $\$ 2.53 / \mathrm{lb}$.) of nitrogen and the value of fertilizer savings in the following year (because of carryover effect), or zero otherwise. Unlike the nonstochastic plateau, optimal nitrogen levels vary for the stochastic plateau given nitrogen-to-cotton price ratios and variance of plateau. Table 4 shows optimal nitrogen levels and corresponding expected

\footnotetext{
${ }^{1}$ For the sake of convenience, we used total nitrogen (applied nitrogen plus carryover nitrogen) to fit the residual nitrogen as a carryover function in the dynamic optimization approach. We found the carryover coefficient for total nitrogen to be 0.21 with a standard error of 0.02 .
} 
Table 4. Profit-maximizing total nitrogen, cotton yield, and recommended applied nitrogen scenarios with stochastic plateau function

\begin{tabular}{|c|c|c|c|c|c|}
\hline \multirow[b]{2}{*}{ Nitrogen Price (\$/lb.) } & \multicolumn{5}{|c|}{ Cotton Price $(\$ / \mathrm{lb})}$. \\
\hline & $\$ 0.39$ & $\$ 0.52$ & $\$ 0.65$ & $\$ 0.78$ & $\$ 0.91$ \\
\hline \multicolumn{6}{|l|}{$\$ 0.30$} \\
\hline Profit-maximizing total N (lb./acre) & 142 & 151 & 157 & 162 & 166 \\
\hline Profit-maximizing yield (lb./acre) & 1,205 & 1,212 & 1,215 & 1,217 & 1,218 \\
\hline Recommended applied N (lb./acre) & 101 & 109 & 115 & 119 & 123 \\
\hline \multicolumn{6}{|l|}{$\$ 0.40$} \\
\hline Profit-maximizing N level (lb./acre) & 133 & 142 & 149 & 155 & 159 \\
\hline Profit-maximizing yield (lb./acre) & 1,197 & 1,205 & 1,210 & 1,214 & 1,216 \\
\hline Recommended applied N (lb./acre) & 92 & 101 & 108 & 112 & 116 \\
\hline \multicolumn{6}{|l|}{$\$ 0.50$} \\
\hline Profit-maximizing total N (lb./acre) & 124 & 135 & 142 & 148 & 153 \\
\hline Profit-maximizing yield (lb./acre) & 1,187 & 1,199 & 1,205 & 1,210 & 1,213 \\
\hline Recommended applied N (lb./acre) & 85 & 95 & 101 & 106 & 110 \\
\hline \multicolumn{6}{|l|}{$\$ 0.60$} \\
\hline Profit-maximizing total N (lb./acre) & 116 & 128 & 136 & 142 & 147 \\
\hline Profit-maximizing yield (lb./acre) & 1,176 & 1,192 & 1,200 & 1,205 & 1,209 \\
\hline Recommended applied N (lb./acre) & 78 & 89 & 96 & 101 & 106 \\
\hline \multicolumn{6}{|l|}{$\$ 0.70$} \\
\hline Profit-maximizing N level (lb./acre) & 109 & 122 & 131 & 137 & 142 \\
\hline Profit-maximizing yield (lb./acre) & 1,164 & 1,185 & 1,195 & 1,201 & 1,205 \\
\hline Recommended applied N (lb./acre) & 71 & 83 & 91 & 97 & 101 \\
\hline
\end{tabular}

Notes: Profit-maximizing yield corresponds to total nitrogen levels. Recommended level of nitrogen application is derived from per acre dynamic optimization of applied nitrogen with stochastic plateau function that maximizes the net present value over a 10 -year planning period. This was calculated as profit-maximizing total nitrogen less a steady-state level of carryover nitrogen when considering soil test information.

maximum yield for 25 sets of cotton and nitrogen prices. The optimal level of total nitrogen ranged between 109 and $166 \mathrm{lb}$./acre when nitrogen-to-cotton price ratios ranged from 0.32 to 1.79 . With the historical price scenarios, the total optimal nitrogen fertility was estimated to be $142 \mathrm{lb}$./acre. Once cotton yield response and carryover dynamics are known, a producer can determine the most profitable level of nitrogen to be applied in the current production year. For instance, a producer who considers carryover nitrogen information in nitrogen application decision rules can maintain the amount of nitrogen available for plant uptake by applying variable amounts annually.

Table 4 further depicts the expected profit-maximizing levels of nitrogen fertilizer application considering LRSP as the suitable functional form for 25 alternative cotton-nitrogen price scenarios. Dynamic optimization provides the optimal levels of nitrogen for augmentation, which is the difference between total nitrogen required to achieve plateau and residual nitrate nitrogen available in the soil because of carryover effects of the previous year's total nitrogen. The expected optimal nitrogen application, which maximized NPV, ranged from $71 \mathrm{lb}$./acre to $123 \mathrm{lb}$./acre depending on a given nitrogen-to-cotton price scenario. The lowest optimum nitrogen application level (i.e., $71 \mathrm{lb}$./acre) was obtained with a higher nitrogen-to-cotton price ratio (1.79) and 


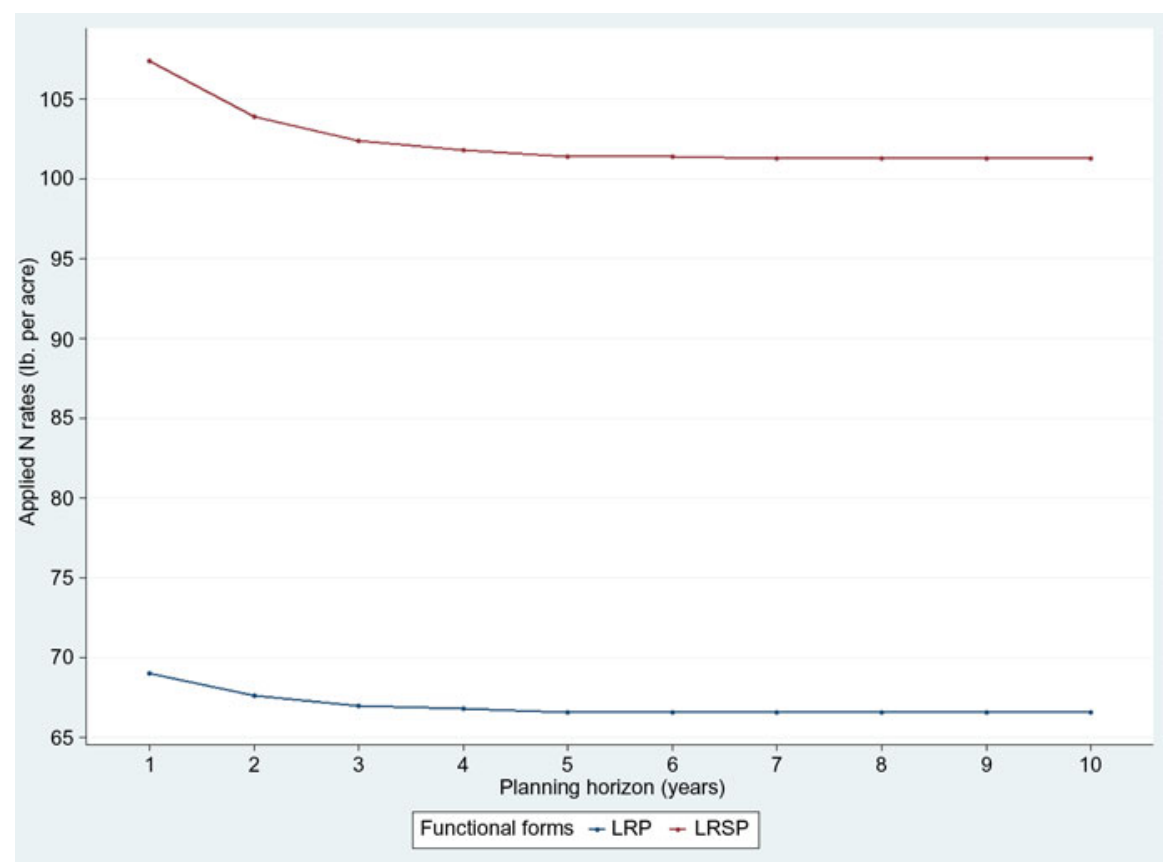

Figure 1. Steady-state optimal levels of applied nitrogen across periods with stochastic and deterministic plateau functions, assuming residual nitrogen of $35 \mathrm{lb}$./acre as a starting point.

Note: LRP, linear response plateau; LRSP, linear response stochastic plateau.

vice versa. Under the current input-output price combinations ( $\$ 0.50$ and $\$ 0.65)$, the steady-state optimum level of applied nitrogen was $101 \mathrm{lb}$./acre. Thus, $101 \mathrm{lb}$. of nitrogen applied in the current production year produced 2.54 bales of cotton. ${ }^{2}$ As such, the optimum nitrogen recommendation is to apply approximately $40 \mathrm{lb}$. of nitrogen for each bale of cotton production. Bronson (2008) also showed that $40 \mathrm{lb}$. of total nitrogen was required to produce 1 bale of lint in West Texas, regardless of cotton variety or irrigation system. However, Hons et al. (2003) and Lemon et al. (2009) recommended $50 \mathrm{lb}$. of nitrogen per bale of cotton production from all sources. Nitrogen application decision rules should consider quantities of residual soil nitrogen, nitrogen in irrigation water, and plant-available nitrogen resulting from natural phenomena such as decay of organic matter. Contribution of nitrate nitrogen via irrigation water was unlikely at the study location; thus, differences in findings from this study and prior work are attributed to cultivar genetic performance.

Under a historical price scenario, the optimal levels of nitrogen were lower with deterministic plateau than with stochastic plateau because $c /\left(p \beta_{1}\right)$ was always less than 0.5 , a condition generally used to compare the nitrogen requirement for profit maximization between stochastic and nonstochastic models. Under historical nitrogen-to-cotton price ratio scenarios (i.e., price ratios in the range of 0.5 to 1 , if $\beta_{1}>2$ ), the LRP functional form underestimates the optimal nitrogen application levels for cotton production.

With dynamic optimization using parameter estimate yield functions, it is important to highlight that optimal nitrogen application levels vary across periods for a given nitrogen-to-cotton price ratio assuming a fixed amount of initial nitrogen residual. Figure 1 depicts optimal levels of applied nitrogen dynamics using LRP and LRSP functions over a 10-year planning period when nitrogen and cotton prices are $\$ 0.50$ and $\$ 0.65 / \mathrm{lb}$., respectively, and assuming a $35-\mathrm{lb}$./acre initial

\footnotetext{
${ }^{2}$ Average yield of cotton in our data was 2.54 bales/acre.
} 


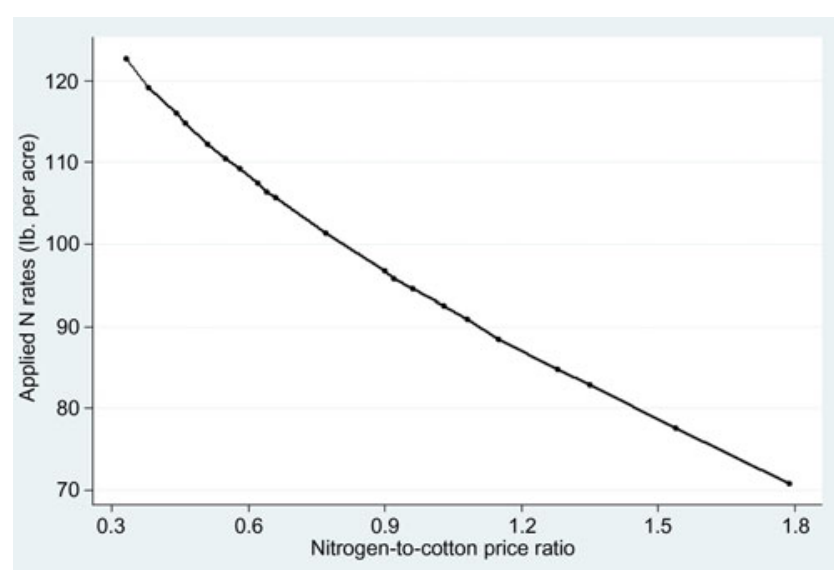

Figure 2. Relationship between applied nitrogen rates and nitrogen-to-cotton price ratios from the stochastic plateau function, assuming $35 \mathrm{lb}$./acre initial nitrogen residual.

nitrogen residual. Considering the LRP functional form, it shows that $69 \mathrm{lb}$./acre of applied nitrogen in the first year of the planning period is optimal, with application rate decreased until the steady-state optimal level of applied nitrogen, $67 \mathrm{lb}$./acre, is achieved, which is far below the current recommendation level. In contrast, when the LRSP functional form is assumed, given 35-lb./acre initial residual nitrogen, $107 \mathrm{lb}$./acre of applied nitrogen in the first year of the planning period would be optimal, with application rate decreased until a steady-state optimal nitrogen level of $101 \mathrm{lb}$./acre is reached.

The optimization model solves for specific input-output price combinations, but discrete combinations may vary substantially, so that a generalized relationship based on relative, rather than absolute, price scenarios could be more useful. Accordingly, a generalization of optimal nitrogen application levels was derived by regressing the optimal nitrogen application against the nitrogento-cotton price ratios. The 25 sets of optimal applied nitrogen levels along with their corresponding nitrogen-to-cotton price ratios are listed in Table 4. Figure 2 depicts the relationship between these optimal decision rules of nitrogen application and nitrogen-to-cotton price ratio. As expected, results indicate that the higher the nitrogen-to-cotton price ratio, the lower the optimal level of nitrogen applied.

The Texas A\&M AgriLife Extension Service showed that the average nitrogen-to-cotton price ratio in the SHPT ranged from 0.5 to 1.0 between 2005 and 2015. At these historical price ratios, optimal nitrogen application levels lie in a range of $95 \mathrm{lb}$./acre to $112 \mathrm{lb}$./acre. Nevertheless, the current producer practice of nitrogen use in the SHPT is to apply $125 \mathrm{lb}$./acre regardless of prices, which is clearly much higher than any of these optimal application rates. This also suggests that if nitrogen-to-cotton price ratios remain close to the historical ratios, and if decision makers follow the nitrogen application optimal decision rules based on the LRSP model, cotton yield would be optimized and cotton production would be a more profitable enterprise. The optimal level of nitrogen application based on LRP models does not vary with nitrogen-to-cotton price ratios; rather, it remains constant until it satisfies the condition given in equation 2.

\subsection{Net present values and valuation of carryover nitrogen}

The empirical distributions of NPV for each of the 25 dynamic models, considering LRSP and LRP functional forms, are presented in Table 5. The benefit of using the LRSP model over the LRP model can be observed in the differences in expected NPV between these two models. Using LRSP functional form, substantially higher NPVs could be achieved. These increased NPVs ranged from $\$ 26$ to $\$ 1,571$ /acre. Furthermore, if NPVs are evaluated at the average price combinations, the loss to producers from using LRP to predict optimal nitrogen application levels would 
Table 5. Net present value (NPV) of returns from dynamic optimization of applied nitrogen using stochastic (LRSP) and deterministic (LRP) plateau functions

\begin{tabular}{|c|c|c|c|c|c|c|c|c|c|c|}
\hline \multicolumn{11}{|c|}{ NPV of Returns (\$/acre, 10-year planning horizon) } \\
\hline \multirow{3}{*}{$\begin{array}{l}\text { Nitrogen } \\
\text { Price }(\$ / \mathrm{lb} .)\end{array}$} & \multicolumn{10}{|c|}{ Cotton Price $(\$ / \mathrm{lb})}$. \\
\hline & \multicolumn{2}{|c|}{$\$ 0.39$} & \multicolumn{2}{|c|}{$\$ 0.52$} & \multicolumn{2}{|c|}{$\$ 0.65$} & \multicolumn{2}{|c|}{$\$ 0.78$} & \multicolumn{2}{|c|}{$\$ 0.91$} \\
\hline & LRSP & LRP & LRSP & LRP & LRSP & LRP & LRSP & LRP & LRSP & LRP \\
\hline$\$ 0.30$ & 3,911 & 3,543 & 5,414 & 4,776 & 6,941 & 6,009 & 8,486 & 7,241 & 10,046 & 8,475 \\
\hline$\$ 0.40$ & 3,744 & 3,491 & 5,215 & 4,724 & 6,714 & 5,957 & 8,233 & 7,189 & 9,768 & 8,423 \\
\hline$\$ 0.50$ & 3,601 & 3,440 & 5,044 & 4,672 & 6,519 & 5,905 & 8,016 & 7,138 & 9,529 & 8,371 \\
\hline$\$ 0.60$ & 3,475 & 3,388 & 4,893 & 4,621 & 6,346 & 5,854 & 7,823 & 7,086 & 9,318 & 8,319 \\
\hline$\$ 0.70$ & 3,362 & 3,336 & 4,757 & 4,569 & 6,189 & 5,802 & 7,648 & 7,034 & 9,127 & 8,267 \\
\hline
\end{tabular}

Note: LRP, linear response plateau; LRSP, linear response stochastic plateau.

be $\$ 614 /$ acre, projected over a 10 -year time interval. Additionally, in order to calculate the value of carryover nitrogen, we considered a discount factor of $5 \%$ and carryover coefficient of 0.21 ; thus, the reduction in nitrogen price was found to be $20 \%$ (carryover coefficient, 0.21 , divided by discount factor, 1.05) in the following period.

\section{Conclusion}

Currently available crop production models often combine either the dynamic programming approach with quadratic functions or stochastic plateau functions alone, without accounting for carryover nitrogen in fertilization problems. Selecting inappropriate functional forms or excluding substantial amounts of residual nitrogen from the model may result in imprecise as well as higher-on-average fertilizer recommendation. This research combines stochastic plateau functions with dynamic optimization techniques in order to develop optimal nitrogen decision rules. This article also examines the benefit of using a stochastic plateau function, in conjunction with carryover information, over a deterministic plateau. Specifically, this research combines Tembo et al.'s (2008) stochastic plateau yield function with Kennedy's (1986) dynamic programming model.

The results favor the stochastic plateau function, as it demonstrates a better fit to the data than its deterministic counterpart. Although there is a payoff to using the stochastic plateau function, the amount of payoff depends on the nitrogen-to-cotton price ratio. Unlike the deterministic plateau, profit-maximizing nitrogen level with the stochastic plateau is a function of the variance of plateau random effects and nitrogen-to-cotton price ratios. It should be noted that the LRP function may underestimate the profit-maximizing level of nitrogen under good growing conditions and may do the opposite under poor growing conditions. This result backs the finding of Tembo et al. (2008) who stated that "use of a stochastic plateau provides insight into why farmers may apply more or less nitrogen than would appear optimal" (p. 432).

It is important to note that the results derived in this study may be used with caution in other geographic areas because of the regional differences in climatic conditions, soil types, and production practices. Nevertheless, the approaches used in this study are applicable for the evaluation of crop production efficiency through optimal input application decision rules in other geographic locations and/or in other crop production systems.

The findings of this study are particularly important in light of escalating nitrogen prices, as well as the serious environmental challenge of managing nitrate contamination in groundwater. Moreover, this research considered the plateau year random effect because of year-to-year 
variation in yield plateau inflicted by environmental and weather conditions. Further research should include field plateau random effects to capture field-to-field variation of yield plateau for multiple field locations.

The results of this study provide useful insight into the value of nitrogen carryover information when using stochastic versus deterministic plateau functions. Reduction in nitrogen usage, based on carryover information, may help cotton farmers improve their profits, all else remaining constant. Additionally, negative environmental consequences resulting from the overapplication of nitrogen may be avoided.

Acknowledgements. The authors gratefully acknowledge the comments of three anonymous reviewers, which contributed to the improvement of this paper.

\section{References}

Ackello-Ogutu, C., Q. Paris, and W.A. Williams. "Testing a Von Liebig Crop Response Function against Polynomial Specifications." American Journal of Agricultural Economics 67, 4(1985):873-80.

Anderson, J.R. "Economic Interpretation of Fertilizer Response Data." Agricultural Economics 35(1967):43-57.

Anderson, R.L., and L.A. Nelson. "A Family of Models Involving Intersecting Straight Lines and Concomitant Experimental Designs Useful in Evaluating Response to Fertilizer Nutrients." Biometrics 31, 2(1975):303-18.

Asci, S., T. Borisova, and J.J. VanSickle. "Role of Economics in Developing Fertilizer Best Management Practices." Agricultural Systems 152(April 2015):251-61.

Babcock, B.A., and A.M. Blackmer. "The Ex Post Relationship between Growing Conditions and Optimal Fertilizer Levels." Review of Agricultural Economics 16, 3(1994):353-62.

Bellman, R. “A Markovian Decision Process.” Journal of Mathematics and Mechanics 6, 5(1957):679-84.

Berck, P., and G. Helfand. "Reconciling the Von Liebig and Differentiable Crop Production Functions." American Journal of Agricultural Economics 72, 4(1990):985-96.

Biermacher, J.T., B.W. Brorsen, F.M. Epplin, J.B. Solie, and W.R. Raun. "The Economic Potential of Precision Nitrogen Application with Wheat Based on Plant Sensing." Agricultural Economics 40, 4(2009): 397-407.

Boyer, C.N., B.W. Brorsen, W.R. Raun, D.B. Arnall, and J.B. Solie. "Efficiency of Pre-Plant, Topdress, and Variable Rate Application of Nitrogen in Winter Wheat." Journal of Plant Nutrition 35, 12(2012):1776-90.

Boyer, C.N., J.A. Larson, R.K. Roberts, M.A. McClure, D.D. Tyler, and S.A. Smith. "Effects of Recent Corn and Energy Prices on Irrigation Investment in the Humid Climate of Tennessee." Journal of Agricultural and Applied Economics 47, 1(2015):105-22.

Boyer, C.N., J.A. Larson, R.K. Roberts, A.T. McClure, D.D. Tyler, and V. Zhou. "Stochastic Corn Yield Response Functions to Nitrogen for Corn after Corn, Corn after Cotton, and Corn after Soybeans." Journal of Agricultural and Applied Economics 45, 4(2013):669-81.

Bronson, K.F. "Nitrogen Use Efficiency of Cotton Varies with Irrigation System.” Better Crops 92, 4(2008):20-22.

Bronson, K.F., J.D. Booker, J.P. Bordovsky, J.W. Keeling, T.A. Wheeler, R.K. Boman, M.N. Parajulee, E. Segarra, and R.L. Nichols. "Site-Specific Irrigation and Nitrogen Management for Cotton Production in the Southern High Plains." Agronomy Journal 98, 1(2006):212-19.

Brorsen, B.W., and F.B. Ouedraogo. "Using Bayesian Estimation Methods to Determine Optimal Levels of Nitrogen Fertilization." Paper presented at the International Conference of Agricultural Economists, Milan, Italy, August 8-14, 2015.

Brorsen, B.W., and F.G.C. Richter. "Experimental Designs for Estimating Plateau-Type Production Functions and Economically Optimal Input Levels." Journal of Productivity Analysis 38, 1(2012):45-52.

Cate, R.B., and LA. Nelson. "A Simple Statistical Procedure for Partitioning Soil Test Correlation Data into Two Classes." Soil Science Society of America Journal 35, 4(1971):858-60.

Cerrato, M.E., and A.M. Blackmer. "Comparison of Models for Describing Corn Yield Response to Nitrogen Fertilizer." Agronomy Journal 82, 1(1990):138-43.

Cox, F.R. "Economic Phosphorus Fertilization Using a Linear Response and Plateau Function." Communication in Soil Science and Plant Analysis 27, 3-4(1996):531-43.

Frank, M.D., B.R. Beattie, and M.E. Embleton. “A Comparison of Alternative Crop Response Models.” American Journal of Agricultural Economics 72, 3(1990):597-603.

Fuller, W.A. "Stochastic Fertilizer Production Functions for Continuous Corn." American Journal of Agricultural Economics 47, 1(1965):105-19.

Godden, D.P., and K.R. Helyar. “An Alternative Method for Driving Optimal Fertilizer Rates.” Review of Marketing and Agricultural Economics 48, 2(1980):83-97.

Grimm, S.S., Q. Paris, and W.A. Williams. “A Von Liebig Model for Water and Nitrogen Crop Response.” Western Journal of Agricultural Economics 12, 2(1987):182-92. 
Harmon, X., C.N. Boyer, D.M. Lambert, and J.A. Larson. "Temporal Frequency of Soil Test Information Effects on Returns to Potassium Fertilization in Cotton Production." Journal of Agricultural and Applied Economics 49, 2(2017):251-72.

Harmon, X., C.N. Boyer, D.M. Lambert, J.A. Larson, and C.O. Gwathmey. "Comparing the Value of Soil Test Information Using Deterministic and Stochastic Yield Response Plateau Functions.” Journal of Agricultural and Resource Economics 41, 2(2016):307-23.

Harper, D.C., D.M. Lambert, J.A. Larson, and C.O. Gwathmey. "Potassium Carryover Dynamics and Optimal Application Policies in Cotton Production.” Agricultural Systems 106, 1(2012):84-93.

Heady, E.O., and J. Dillon. Agricultural Production Functions. Ames: Iowa State University Press, 1961.

Hons, F.M., R.G. Lemon, and M.L. McFarland. "Cotton Nitrogen Management in the Southwest Region." Paper Presented at the 2003 Beltwide Cotton Conferences, Nashville, TN, January 6-10, 2003.

Huang, W.Y., Y.C. Lu, and N.D. Uri. "An Assessment of Soil Nitrogen Testing Considering the Carry-Over Effect." Applied Mathematical Modeling 25, 10(2001):843-60.

Hurley, T.M., K. Oishi, and G.L. Malzer. "Estimating the Potential Value of Variable Rate Nitrogen Applications: A Comparison of Spatial Econometric and Geostatistical Models." Journal of Agricultural and Resource Economics 30, 2(2005):231-49.

Jomini, P.A., R.D. Deuson, J. Lowenberg-DeBoer, and A. Bationo. "Modelling Stochastic Crop Response to Fertilisation When Carryover Matters.” Agricultural Economics 6, 2(1991):97-113.

Kaitibie, S., F.M. Epplin, B.W. Brorsen, G.W. Horn, E.G. Krenzer, and S.I. Paisley. "Optimal Stocking Density for Dual-Purpose Winter Wheat Production.” Journal of Agricultural Applied Economics 35, 1(2003):29-38.

Kaitibie, S., W.E. Nganje, B.W. Brorsen, and F.M. Epplin. “A Cox Parametric Bootstrap Test of the Von Liebig Hypothesis." Canadian Journal of Agricultural Economics 55, 1(2007):15-25.

Kennedy, J.O.S. "Application of Dynamic Programming to Agriculture, Forestry, and Fisheries Review and Prognosis." Review of Marketing and Agricultural Economics 49, 3(1981):141-73.

Kennedy, J.O.S. "Rules for Optimal Fertilizer Carryover: An Alternative Explanation.” Review of Marketing and Agricultural Economics 54, 2(1986):3-10.

Kennedy, J.O.S. "Principles of Dynamic Optimization in Resource Management." Review of Marketing and Agricultural Economics 2, 1(1988):57-72.

Kennedy, J.O.S., I.F. Whan, R. Jackson, and J.L. Dillon. "Optimal Fertilizer Carryover and Crop Recycling Policies for a Tropical Grain Crop.” Australian Journal of Agricultural Economics 17, 2(1973):104-13.

Lanzer, E.A., and Q. Paris. "A New Analytical Framework for the Fertilization Problem.” American Journal of Agricultural Economics 63, 1(1981):93-103.

Lemon, R., R. Boman, M. McFarland, B. Bean, T. Provin, and F. Hons. Nitrogen Management in Cotton. College Station: Agrilife Extension, Texas A\&M System, SCS-2009-1, 2009.

Leonard, D., and N. van Long. Optimal Control Theory and Static Optimization in Economics. Cambridge: Cambridge University Press, 1992.

Llewelyn, R.V., and A.M. Featherstone. "A Comparison of Crop Production Functions Using Simulated Data for Irrigated Corn in Western Kansas.” Agricultural Systems 54, 4(1997):521-38.

Makowski, D., and D. Wallach. "It Pays to Base Parameter Estimation on a Realistic Description of Model Errors." Agronomie 22, 2(2002):179-89.

Ouedraogo, F.B., B.W. Brorsen, and D. B. Arnall. “Changing Optimal Nitrogen Levels in Cotton.” Journal of Cotton Science 20, 1(2016):18-25.

Parajulee, M.N., and R.B. Shrestha. "Metapopulation Approach for Landscape Level Management of Western Tarnished Plant Bug, Lygus hesperus, in Texas (Hemiptera, Miridae)." Plant Protection Journal (Acta Phytophylacica Sinica) 41(2014):761-68.

Paris, Q. “The Von Liebig Hypothesis.” American Journal of Agricultural Economics 74, 4(1992):1019-28.

Paris, Q., and K. Knapp. "Estimation of Von Liebig Response Functions." American Journal of Agricultural Economics 71, 1(1989):178-86.

Park, S.C., A. Stoecker, J.A. Hattey, and J.C. Turner. "Long-Term Profitability of Animal Manure Using Optimal Nitrogen Application Rate." Paper presented at the Southern Agricultural Economics Association Annual Meeting, Mobile, AL, February 4-7, 2007.

Perrin, R.K. "The Value of Information and the Value of Theoretical Models in Crop Response Research." American Journal of Agricultural Economics 58(1976):54-61.

Raun, W.R., J.B. Solie, G.V. Johnson, M.L. Stone, R.W. Mullen, K.W. Freeman, W.E. Thomason, and E.V. Lukina. "Improving Nitrogen Use Efficiency in Cereal Grain Production with Optical Sensing and Variable Rate Application." Agronomy Journal 94, 4(2002):815-20.

Raun, W.R., J.B. Solie, G.V. Johnson, M.L. Stone, R.W. Whitney, H.L. Lees, H. Sembiring, and S.B. Phillips. "Microvariability in Soil Test, Plant Nutrient, and Yield Parameters in Bermudagrass." Soil Science Society of America Journal 62, 3(1998):683-90. 
Roberts, R.K., B.C. English, and J.A. Larson. "The Variable-Rate Input Application Decision for Multiple Inputs with Interactions." Journal of Agricultural and Resource Economics 31, 2(2006):391-413.

SAS Institute Inc. SAS/STAT User's Guide, Version 9.3. Cary, NC: SAS Institute Inc., 2013.

SAS Institute Inc. SAS/STAT User's Guide, Version 9.3. Cary, NC: SAS Institute Inc., 2016.

Segarra, E., E.D. Ethridge, C.R. Deussen, and A.B. Onken. "Nitrogen Carryover Impacts in Irrigated Cotton Production, Southern High Plains of Texas.” Western Journal of Agricultural Economics 14, 2(1989):300-309.

Sher, A., and I. Amir. "Optimization with Fuzzy Constraints in Agricultural Production Planning." Agricultural Systems 45, 4(1994):421-41.

Smith, J. South Plains District, Cotton Enterprise Budget, 2016. College Station: Texas A\&M AgriLife Extension Service, 2016. Internet site: https://agecoext.tamu.edu/wp-content/uploads/2016/01/2016D2CottonPivot.pdf (Accessed January 10, 2019)

Stoecker, A.L., and A.B. Onken. "Optimal Fertilizer Nitrogen and Residual Nitrate-Nitrogen Levels for Irrigated Corn and Effects of Nitrogen Limitations: An Economic Analysis.” Journal of Production Agriculture 2, 4(1989):309-17.

Tembo, G., B.W. Brorsen, F.M. Epplin, and E. Tostão. “Crop Input Response Functions with Stochastic Plateaus.” American Journal of Agricultural Economics 90, 2(2008):424-34.

Tumusiime, E., B.W. Brorsen, J. Mosali, J. Johnson, J. Locke, and J.T. Biermache. "Determining Optimal Levels of Nitrogen Fertilizer Using Random Parameter Models." Journal of Agricultural and Applied Economics 43, 4(2011):541-52.

U.S. Department of Agriculture, National Agricultural Statistics Service (USDA-NASS). Prospective Plantings. Washington, DC: USDA-NASS, 2018. Internet site: https://downloads.usda.library.cornell.edu/usda-esmis/files/ x633f100h/wm117r67h/n870zt26v/ProsPlan-03-29-2018.pdf (Accessed January 10, 2019).

Von Liebig, J. Die Grundsätze der Agricultur-Chemie mit Rücksicht auf die in England angestellten untersuchungen. Braunschweig, Germany: Friedrick Vieweg und Sohn, 1855.

Waugh, D.L., R.B. Cate, and L.A. Nelson. Discontinuous Models for Rapid Correlation, Interpretation and Utilization of Soil Analysis and Fertilizer Response Data. Raleigh: Soil Fertility Evaluation and Improvement Program, North Carolina State University, Technical Bulletin No. 7, 1973.

Wolfinger, R.D. "Fitting Nonlinear Mixed Models with the New NLMIXED Procedure." Proceedings of the 24th Annual SAS User's Group International Conference. Cary, NC: SAS Institute Inc., 1999, Paper 287.

Xu, Z., Z. Guan, T.S. Jayne, and R. Black. "Factors Influencing the Profitability of Fertilizer Use on Maize in Zambia." Agricultural Economics 40, 4(2009):437-46.

Zhou, X.V., C.D. Clark, D.M. Lambert, B.C. English, J.A. Larson, and C.N. Boyer. "Biomass Supply and Nutrient Runoff Abatement under Alternative Biofuel Feedstock Production Subsidies." Agricultural Systems 139(October 2015):250-59.

Cite this article: Dhakal C, Lange K, Parajulee MN, and Segarra E (2019). Dynamic Optimization of Nitrogen in Plateau Cotton Yield Functions with Nitrogen Carryover Considerations. Journal of Agricultural and Applied Economics 51,

385-401. https://doi.org/10.1017/aae.2019.6 